\title{
An Invitation to Our Medical Colleagues: Work with Us
}

\author{
Henry Buchwald • Nicola Scopinaro
}

Published online: 4 September 2010

(C) Springer Science+Business Media, LLC 2010

The June 26-July 2, 2010 issue of The Lancet inspired one of us (HB) to write the editors of The Lancet the following letter (references excluded):

\section{Dear Sir:}

I read your June 26-July 2, 2010 issue, dedicated to diabetes, cover-to-cover, reviewed the cited references, and carefully studied The Lancet editorial. To my amazement, there was not one mention of metabolic/ bariatric surgery, the only proven method of resolving the clinical and laboratory manifestations of type 2 diabetes in about $80 \%$ of patients [1-4]. Though this technology is not suitable or available to all type 2 diabetics, it is an alternative for millions of people and, most importantly, metabolic/bariatric surgery is a clinical laboratory for diabetes research.

The Lancet reflects clinical acumen in this critical area of diabetes management and, thereby, serves the role of a global university for educating the medical profession. This role makes it imperative that The Lancet not ignore and omit mention of the evidencebased literature findings contributed by metabolic/ bariatric surgery.

I fully agree with the statement on your cover: "Medicine might be winning the battle of glucose control, but is losing the war against diabetes." Medicine will continue to lose this war until medical

H. Buchwald $(\bowtie)$

Surgery and Biomedical Engineering, University of Minnesota,

St. Paul, MN, USA

e-mail: buchw001@umn.edu

N. Scopinaro

University of Genoa,

Genoa, Italy practitioners use their cognitive abilities to help to understand the findings of their surgical colleagues, and work together with surgeons to treat, research, and understand the disease of diabetes. Only then will the lamentations end and the war against diabetes be won.

At first, The Lancet asked that the letter above be resubmitted in a different electronic format. We complied. The letter was subsequently rejected via a form email after "in-house review," reassuring the sender as follows: "...please be assured that we have nevertheless considered it carefully and probably had to refuse it because we have simply received too much good material."

Why was this letter not good enough material? Was it because the letter criticized the journal and its editors? Was it because the letter was painfully factual in its content? Or was it because The Lancet's response was symptomatic of an attitude seemingly universal among internists rejecting surgical solutions? The late, brilliant educator (mentor to HB), Columbia Professor of Medicine, Dr. Robert E. Loeb, often stated on rounds that "the first duty of the internist is to keep the patient out of the hands of the surgeon." Unfortunately, this bias continues to prevail.

Yet surgeons have not given up hope for a collegial, working relationship with internists. This would be an excellent time for the hostility between non-surgeons and surgeons to end. We must temper instinct by discourse. We must work together with reason. We must heal this rift.

The discipline of metabolic/bariatric surgery has tried to sponsor cooperation, dialogue, and the adjudication of differences; no group of practitioners has ever tried harder. Metabolic/bariatric surgeons have published hundreds of evidence-based articles on the outcomes of surgery in the management of morbid obesity and the comorbidities of this world pandemic. They have invited internists and basic scientists to their national and international meetings. They have sponsored global specialty meetings on the management 
of type 2 diabetes with non-surgeon invitees outnumbering surgical invitees. Surgeons have studied medical therapies, credited them, and discussed them. Metabolic/bariatric surgeons have exhaustively attempted to establish understanding and cooperation. They have received little reciprocity from the medical community.

Since this is an editorial and not a review, we will confine our documentation of published data to a short synopsis of exemplary material from only one aspect of metabolic/bariatric surgery therapy; namely, the topic of The Lancet's article-diabetes. We apologize for using some of our own papers as illustration; we have, however, worked in this area for decades. As early as 1986, Scopinaro reported that metabolic/bariatric surgery, specifically biliopancreatic diversion, was effective in correcting type 2 diabetes [1, 2]. In 1995, Pories et al. in a landmark paper titled "Who would have thought it? An operation proves to be the most effective therapy for adult-onset diabetes mellitus," advocated hormonal mechanisms for the effect of gastric bypass, often independent of weight loss, on type 2 diabetes [3]. This effort ushered in the era of planned metabolic surgery for type 2 diabetes.

In a type 2 diabetes rat preparation, Rubino and Marescaux showed that a plastic sleeve within the duodenum, preventing contact of food with the duodenal mucosa, resolved the animals' diabetes; however, when the sleeve was subsequently perforated, the diabetes recurred [4]. Clinical adaptation of this insight soon followed, with the duodenojejunal bypass procedure $[5,6]$, and the sleeve gastrectomy with ileal interposition [7]. Gastric electrode implantations, with total absence of a mechanical or restrictive or malabsorptive mechanism, have been demonstrated to cause only modest weight loss but significant reductions in hemoglobin A1c [8]. Scopinaro has recently performed the biliopancreatic diversion operation on diabetic patients with a BMI $\leq 35 \mathrm{~g} / \mathrm{m}^{2}[2$, $9,10]$ with resolution of the diabetes and only modest weight loss. Comparable findings have been reported by DeMaria et al. in patients undergoing laparoscopic adjustable gastric banding and gastric bypass [11].

Buchwald et al. have published two major meta-analyses of the effect of metabolic/bariatric surgery on type 2 diabetes; both in non-surgical journals with a wide readership [12, 13]. In the first publication in 2004, diabetes was resolved in $76.8 \%$ of patients and resolved or improved in $86.0 \%$ [12]. In the 2009 publication, with a data set of 621 studies, 888 treatment arms, and 135,246 patients, the diabetes resolution rate was $78.1 \%$ [13]. The resolutions rates for less than 2 years and greater than 2 years were essentially the same, demonstrating that the response of type 2 diabetes to bariatric surgery was lasting.

Could this evidence-based literature, and the myriad of confirmatory publications, not have come to the attention of the majority of decision makers in the medical community?
No! We are faced not with a lack of knowledge but with a conscious ignoring of knowledge. Even when cognizance of the effectiveness of metabolic/bariatric surgery is admitted, certain nonsurgical clinicians raise questions concerning the utility of metabolic/bariatric surgery, citing that: metabolic/bariatric-specific procedures are multiple and constantly in flux; the long-term morbidity of metabolic/bariatric surgery is as yet unknown; and, most importantly, a solid understanding of mechanisms of action for these procedures has not been ascertained. Yet, these same individuals have no hesitation: prescribing multiple drugs and several commercial versions of a single class of pharmaceuticals; prescribing drugs after short-duration clinical trials sponsored by pharmaceutical houses; taking for granted continuous revelations of long-term morbidity, and often mortality, following the use of drugs by millions of people; and prescribing drugs that for decades have never had their mechanisms of action explained.

Bariatric/metabolic surgeons perform approximately 220,000 metabolic/bariatric procedures annually in the USA and 344,221 worldwide [14]. Each of their patients holds the secret of why metabolic/bariatric operations cause weight loss. About $20 \%$ of these patients hold the secret of why the metabolic/bariatric operations resolve type 2 diabetes. Each operated patient is a reservoir of information of why obesity and the metabolic syndrome exist. All that is now secret and unknown may be discoverable by simple and safe clinical investigation. Yet every day, these rich human research opportunities to understand and make progress towards the elimination of global epidemics are ignored by our medical colleagues.

Thus, our invitation to our medical colleagues: work with us and not against us. All clinicians should have equal seating at the table of scientific progress and therapeutic decision making. Help the scientific community to understand what we are accomplishing with our surgery. We invite you to use your cognitive abilities, your academic aspirations, your time, your dedication, and your intrinsic desire to gain knowledge of and how to treat type 2 diabetes, as well as the other comorbidities of obesity, and obesity itself. By turning your backs on your surgical colleagues, you are turning your backs on your patients. The millions of afflicted individuals ask and expect better of all of us.

Sincerely yours,

Henry Buchwald, M.D., Ph.D.-Co-Editor-in-Chief, Obesity Surgery, Professor of Surgery and Biomedical Engineering University of Minnesota, USA

Nicola Scopinaro, M.D., F.A.C.S. (Hon.)-Co-Editor-inChief, Obesity Surgery, Professor of Surgery, University of Genoa, Italy 


\section{References}

1. Scopinaro N, Gianetta E, Friedman D, et al. Evolution of biliopancreatic bypass. Clin Nutr. 1986;5(Suppl):137-46.

2. Scopinaro N. Biliopancreatic diversion: mechanisms of action and long-term results. Obes Surg. 2006;16:683-9.

3. Pories WJ, Swanson MS, MacDonald KG, et al. Who would have thought it? An operation proves to be the most effective therapy for adult-onset diabetes mellitus. Ann Surg. 1995;222: 339-50.

4. Rubino F, Marescaux J. Effect of duodenal-jejunal exclusion in a non-obese animal model of type 2 diabetes: a new perspective for an old disease. Ann Surg. 2004;239:1-11.

5. Cohen RV, Schiavon CA, Pinheiro JS, et al. Duodenal-jejunal bypass for the treatment of type 2 diabetes in patients with body mass index of $22-34 \mathrm{~kg} / \mathrm{m}^{2}$ : a report of 2 cases. Surg Obes Rel Dis. 2007;3:195-7.

6. Ramos AC, Galvão Neto MP, de Souza YM, et al. Laparoscopic duodenal-jejunal exclusion in the treatment of type 2 diabetes mellitus in patients with $\mathrm{BMI}<30 \mathrm{~kg} / \mathrm{m}^{2}$ (LBMI). Obes Surg. 2009;19:307-12.

7. DePaula AL, Macedo ALV, Mota BR, et al. Laparoscopic ileal interposition associated to a diverted sleeve gastrectomy is an effective operation for the treatment of type 2 diabetes mellitus patients with BMI 21-29. Surg Endosc. 2009;23:1313-20.

8. Bohdjalian A, Prager G, Aviv R, et al. One-year experience with Tantalus $^{\mathrm{TM}}$ : a new surgical approach to treat morbid obesity. Obes Surg. 2006;16:627-34

9. Scopinaro N, Papadia F, Marinari G, et al. Long-term control of type 2 diabetes mellitus and the other major components of the metabolic syndrome after biliopancreatic diversion in patients with BMI $<35 \mathrm{~kg} / \mathrm{m}^{2}$. Obes Surg. 2007;17:193-4.

10. Scopinaro N, Adami GF, Papadia FS, et al. Effects of biliopancreatic diversion on type 2 diabetes in patients with BMI 25-35. Ann Surg, in press, 2010.

11. DeMaria EJ, Winegar D, Pate V, et al. Early postoperative outcomes of metabolic surgery to treat diabetes from sites participating in the ASMBS Bariatric Surgery Center of Excellence program as reported in the Bariatric Outcomes Longitudinal Database (BOLD). Ann Surg, in press, 2010.

12. Buchwald H, Avidor Y, Braunwald E, et al. Bariatric surgery: a systematic review and meta-analysis. JAMA. 2004;292:1724-37.

13. Buchwald H, Estok R, Fahrbach K, et al. Weight and type 2 diabetes after bariatric surgery: systematic review and metaanalysis. Am J Med. 2009;122:248-56.

14. Buchwald H, Oien D. Metabolic/bariatric surgery worldwide 2008. Obes Surg. 2009;19:1605-11. 